\title{
Predictive Value of miRNA-181a in Pediatric Acute Lymphoblastic Leukemia
}

\author{
Asmaa El Desoky1,2, Hosny Badrawy ${ }^{2 *}$, Dina Ismail Abd El Razik ${ }^{2}$, Khaled F. Riad ${ }^{3}$, \\ Omina N. Abdelhamid ${ }^{3}$, Eman Hassan ${ }^{2}$ \\ ${ }^{1}$ Translational Hematology and Oncology Research (THOR) Department, Learner Institute, Case Western Reserve University, \\ Cleveland, Ohio, USA \\ ${ }^{2}$ Department of Clinical Pathology, South Egypt Cancer Institute, Assiut University, Assiut, Egypt \\ ${ }^{3}$ Department of Pediatric Oncology, South Egypt Cancer Institute, Assiut University, Assiut, Egypt \\ Email: ‘badrawyh@yahoo.com, asmaa_zedan@aun.edu.eg, khaledfraid@gmail.com
}

How to cite this paper: El Desoky, A., Badrawy, H., Abd El Razik, D.I., Riad, K.F., Abdelhamid, O.N. and Hassan, E. (2020) Predictive Value of miRNA-181a in Pediatric Acute Lymphoblastic Leukemia. Journal of Cancer Therapy, 11, 673-682. https://doi.org/10.4236/jct.2020.1111057

Received: October 21, 2020

Accepted: November 15, 2020

Published: November 18, 2020

Copyright (c) 2020 by author(s) and Scientific Research Publishing Inc. This work is licensed under the Creative Commons Attribution International License (CC BY 4.0).

http://creativecommons.org/licenses/by/4.0/

\begin{abstract}
Background: Acute lymphoblastic leukemia (ALL), a common pediatric malignant neoplasia, showed high relapse rate after induction therapy. Some miRNAs have been shown to regulate normal hematopoiesis and their disruption could contribute to leukemogenesis: Recently, specific miRNA, including miR-181a, was shown to be involved in the pathogenesis of ALL, serving as a biomarker for diagnosis and relapse of ALL. Aim of the Study: To evaluate miR-181a expression level as a predictive marker for children with acute lymphoblastic leukemia. Patients and Methods: 40 pediatric ALL patients were included in this study. miR-181a expression was assessed at diagnosis before start of treatment. Samples were either peripheral blood or bone marrow aspirate sample. Patients were evaluated clinically and laboratory after the induction therapy. Results: The remission rate was significantly higher in patients with high miR-181a expression compared to those with low expression $(\mathrm{p}<0.001)$. Conclusion: The expression level of miR-181a was significantly higher in remission group than in non-remission group was and predict good response to induction therapy.
\end{abstract}

\section{Keywords \\ miR-181a, Micro-RNA, ALL}

\section{Introduction}

Acute lymphoblastic leukemia (ALL) is considered the most common pediatric cancer, one in four of all malignancies in children and approximately $75 \%$ of all pediatric leukemia. ALL is characterized by clonal proliferation of B-cell precur- 
sors and/or T-cell precursors and results in accumulation of lymphoblasts in bone marrow (BM) and various extra-medullary sites [1]. Despite the improvement in survival of childhood ALL, non responding or relapsing patients still represent one of the most common causes of death in children. Therefore, early treatment response can predict the risk of relapse and help assigning patients to subsequent risk-adapted therapy [2].

miRNAs are small (typically 18 - 25 nucleotides), single stranded non-coding RNAs that negatively regulate gene expression at the post-transcriptional level. According to the target mRNA, miRNAs serve as tumor suppressors or oncogenes [3]. Recently, specific miRNAs have been reported to be involved in the pathogenesis of leukemia [4]. Many studies have been published on either an individual miRNA or a panel of miRNAs as a diagnostic biomarker in childhood ALL and many of these studies were carried out to find miRNAs as a non-invasive prognostic biomarker [5] [6] [7] [8] [9].

miRNA-181 (miR-181) family encoded by three different transcripts is located on three different chromosomes. MiR-181a and miR-181b cluster together on chromosome 1 and miR-181a2 and miR-181b2 are located on chromosome 9. The miR-181c and miR-181d are on chromosome 19 [10].

miR-181 is known to play a crucial regulatory role in leukocyte cell differentiation and function. It has been shown that miR-181 has a key role in T-cell maturation, particularly at the $\mathrm{CD} 4^{+} \mathrm{CD} 8^{+}$stage of thymocyte development. miR-181 inhibits the expression of genes involved in positive selection and T-cell maturation such as BCL2, CD69, and TCR. These findings support that future studies should focus on miR-181 family in the management of ALL [11]. miR-181a and miR-181b have been reported to be highly expressed in childhood ALL. The sensitivity \& specificity of miR-181a were $86.5 \% \& 93.3 \%$, respectively [12].

In this study, we aim to evaluate the utility of on miR-181a expression as predictive factor, risk stratification and to correlate its expression to the response after induction therapy in childhood ALL.

\section{Patients and Methods}

This prospective cohort study was carried out in Oncological Clinical Pathology Department, South Egypt Cancer Institute (SECI), Assiut, Egypt and included 40 newly diagnosed pediatric acute lymphoblastic leukemia patients. Their ages ranged from 2.5 to 16 years with a mean of $8.6 \pm 3.4$ years. All cases were collected from pediatric oncology clinic of SECI from January 2018 to May 2019.

Diagnosis of ALL patients was established through full history taking, clinical examination, complete blood picture, bone marrow aspirate (BMA) examination, flow cytometric and cytogenetic analysis. All the cases met the ALL WHO 2016 diagnostic criteria. Patients have been evaluated for the response after induction therapy clinically, by complete blood picture and bone marrow aspirate examination. We divided pediatric ALL cases after induction therapy to: 
- Remission cases (complete and incomplete) in which they are clinically free, normal $\mathrm{CBC}$ and normal BMA after induction phase (blast cells less than $10 \%)$.

- Non remission cases include: Relapsed cases in which (clinically show persistent or relapsed organomegaly or lymphadenopathy, persistent or relapsed cytopenia and BMA shows blast cell $10 \%$ or more) and died cases include cases died during or just after induction phase.

Written informed consent was taken from all patients and study protocols were approved by the ethical committee, South Egypt Cancer Institute, Assiut University, Egypt.

\subsection{Specific Laboratory Investigation}

Before start of treatment and after established diagnosis, miR-181a expression is measured in peripheral blood or bone marrow aspirate sample by real time PCR.

\subsection{Measurement of miR-181a}

$2 \mathrm{ml}$ of bone marrow aspirate or peripheral venous blood sample were withdrawn in sterile vacationer tubes containing EDTA under complete aseptic conditions. miRNA was extracted from samples by miRNeasy Mini kit (Qiagen, Germany) extraction kit. Using TaqMan ${ }^{\circledR}$ MicroRNA Reverse Transcription (RT) Kit and TaqMan ${ }^{\oplus}$ Small RNA Assay (applied biosystems, USA), specific miRNA is accurately detected and converted to cDNA. Then, Real-time PCR (q-PCR) was performed with TaqMan ${ }^{\circledR}$ Universal Master Mix (Thermo Fisher Scientific, USA) and TaqMan ${ }^{\circledR}$ specific Assay using 7500 Fast Real-Time PCR System (Thermo Fisher Scientific, USA).

The relative expression of miR-181a was presented as the fold change using $2^{-\triangle \Delta C T}$ method, normalized to endogenous housekeeping RNU6B gene and relative to the normal control subject included in the experiment.

\section{Statistical Analysis}

Qualitative data were described using number and percent and quantitative data using mean \pm SD. All analyses were conducted using SPSS software version 21 . Univariant factors were analyzed using the chi-square test for categorical variables except variables with less than 5 in one cell in which fisher exact test was done for them. Mann Whitney test was done for quantitative variable. In all statistical tests, level of significance of 0.05 was used, below which the results are considered statistically significant.

\section{Results}

\subsection{Clinical and Laboratories Features of the Study Group}

The study was done on 40 newly diagnosed pediatric ALL patients, which were evaluated for miR-181a expression relative to normal healthy, same sex and age children. Clinical and laboratories features of the study group are seen in Table 1. 
Table 1. Clinical and laboratories features of the cases. Mean \pm SD or Number (\%).

\begin{tabular}{|c|c|}
\hline Parameter & Finding \\
\hline Number & 40 \\
\hline Age (year) & $6.8 \pm 3.4$ \\
\hline \multicolumn{2}{|l|}{ Gender } \\
\hline Male & $22(55 \%)$ \\
\hline Female & $18(45 \%)$ \\
\hline \multicolumn{2}{|l|}{ Hepatosplenomegaly } \\
\hline Yes & $14(35 \%)$ \\
\hline No & $26(65 \%)$ \\
\hline \multicolumn{2}{|l|}{ Generalized lymphadenopathy } \\
\hline Yes & $15(37.5 \%)$ \\
\hline No & $25(62.5 \%)$ \\
\hline \multicolumn{2}{|l|}{ WBCs } \\
\hline less than $50,000 / \mathrm{mm}^{3}$ & $11(27.5 \%)$ \\
\hline Equal or more than $50,000 / \mathrm{mm}^{3}$ & $29(72.5 \%)$ \\
\hline \multicolumn{2}{|l|}{ Immunophenotyping } \\
\hline B-ALL & $33(82.5 \%)$ \\
\hline T-ALL & $7(17.5 \%)$ \\
\hline \multicolumn{2}{|c|}{ Philadelphia chromosome BCR-ABL1/t $(9 ; 22)$ (q34; q11) } \\
\hline Positive & $20(50 \%)$ \\
\hline Negative & $20(50 \%)$ \\
\hline
\end{tabular}

$\mathrm{ALL}=$ Acute lymphoblastic leukemia; $\mathrm{B}-\mathrm{ALL}=\mathrm{B}$-lineage acute lymphoblastic leukemia; $\mathrm{T}$-ALL $=\mathrm{T}$-lineage acute lymphoblastic leukemia.

Among 40 newly diagnosed ALL, there are 22 (55\%) males and 18 (45\%) females. Also, 14 cases (35\%) have hepatosplenomegaly and 15 cases (37.5\%) have generalized lymphadenopathy.

As regard to WBCs count, 11 (27.5\%) show WBCs count less than $50,000 / \mathrm{mm}^{3}$ and $29(72.5 \%)$ show WBCs count more than or equal to $50,000 / \mathrm{mm}^{3}$.

Among 40 cases of pediatric ALL, 33 (82.5\%) cases are B cell phenotype, 7 (17.5\%) cases are $\mathrm{T}$ cell phenotype by flow cytometry. As regard to Philadelphia chromosome $\mathrm{t}(9 ; 22)$ (q34; q11) BCR-ABL1 cytogenetic analysis by FISH, there are $20(50 \%)$ cases positive and $20(50 \%)$ cases are negative.

\subsection{Expression of miR-181a in 40 Newly Diagnosed ALL Cases}

We found that 33 patients (82.5\%) show over expression of miR-181a with RQ $(57.6 \pm 170.5)$ and $7(17.5 \%)$ of patients show under expression of miR-181a with RQ $(0.43 \pm 0.24)($ cut off $=1)$ (Table 2$)$. 
Table 2. Expression of miR-181a in 40 newly diagnosed ALL cases.

\begin{tabular}{cc}
\hline Parameter & Finding \\
Number & 40 \\
miR-181a expression & $33(82.5 \%)$ \\
Over expression & $7(17.5 \%)$ \\
Under expression & \\
miR-181a (RQ) & \\
Over expression & \\
Mean \pm SD & $57.6 \pm 170.5$ \\
Min - max & $1.2-987$ \\
Under expression & \\
Mean \pm SD & $0.43 \pm 0.24$ \\
Min - max & $0.11-0.78$ \\
\hline
\end{tabular}

RQ: relative quantification or fold change by RT-qPCR.

\subsection{Association between miR-181a Expression and Clinic-Laboratories Features of Cases}

No significant difference between high and low expresser of miR-181a as regard to age, sex, hepatosplenomegaly, generalized lymphadenopathy and WBCs in these patients. Neither were the significant difference between high and low miR-181a expresser as regard to immunophenotyping and $t(9 ; 22)$ (q34; q11) BCR-ABL1 in these patients (Table 3).

\subsection{Outcome of Cases after Induction Therapy and Its Association with miR-181a Expression}

We evaluated cases after induction therapy and found that $26(65 \%)$ of the patients were in remission after the induction therapy and 14 (35\%) of cases were not in remission (Table 4, Figure 1).

We then asked whether miR-181a could serve as the biomarkers for prediction of leukemia remission and found that there is a significant association between over expression of miR-181a and the remission after induction therapy ( $\mathrm{p}$ $<0.001)$.

\section{Discussion}

miR-181a was reported to be over expressed in childhood ALL. miR-181a is known to play a regulatory role in leukocyte cell differentiation and function [9]. These findings support the suggestion miR-181a can be used as a predictive factor in the management of ALL.

We conducted this study to assess the expression of miR-181a in childhood ALL, its clinical association with clinic-pathological features of cases and the response after induction therapy. 
Table 3. Association between miR-181a expression and clinic-laboratories features of 40 ALL cases.

\begin{tabular}{|c|c|c|c|}
\hline Parameter & Over expression & Under expression & $\mathbf{P}$ \\
\hline Number & 33 & 7 & \\
\hline \multicolumn{4}{|l|}{ Age (year) } \\
\hline Mean \pm SD & $6.9 \pm 3.6$ & $6.1 \pm 2.5$ & 0.76 \\
\hline \multicolumn{4}{|l|}{ Gender } \\
\hline Male & $19(57.6 \%)$ & $3(42.9 \%)$ & 0.68 \\
\hline Female & $14(42.4 \%)$ & $4(57.1 \%)$ & \\
\hline \multicolumn{4}{|l|}{ Hepatosplenomegaly } \\
\hline Yes & $12(36.4 \%)$ & $2(28.6 \%)$ & 0.99 \\
\hline No & $21(63.6 \%)$ & $5(71.4 \%)$ & \\
\hline \multicolumn{4}{|l|}{ Generalized lymphadenopathy } \\
\hline Yes & $13(39.4 \%)$ & $2(28.6 \%)$ & 0.7 \\
\hline No & $20(60.6 \%)$ & $5(71.4 \%)$ & \\
\hline \multicolumn{4}{|l|}{ WBCs } \\
\hline less than $50,000 / \mathrm{mm}^{3}$ & $22(66.7 \%)$ & $7(100 \%)$ & \\
\hline Equal or more than $50,000 / \mathrm{mm}^{3}$ & $11(33.3 \%)$ & $0(0 \%)$ & 0.16 \\
\hline \multicolumn{4}{|l|}{ Immunophenotyping } \\
\hline B-ALL & $28(84.8 \%)$ & $5(71.4 \%)$ & 0.58 \\
\hline T-ALL & $5(15.2 \%)$ & $2(28.6 \%)$ & \\
\hline \multicolumn{4}{|l|}{$\begin{array}{l}\text { Philadelphia chromosome } \\
\text { BCR-ABL1/t }(9 ; 22)(\mathrm{q} 34 ; \mathrm{q} 11)\end{array}$} \\
\hline Positive & $16(48.5 \%)$ & $4(57.1 \%)$ & 0.99 \\
\hline Negative & $17(51.5 \%)$ & $3(42.9 \%)$ & \\
\hline
\end{tabular}

Significant $\mathrm{p}<0.05$

Table 4. Outcome of cases after induction therapy and its association with miR-181a expression.

\begin{tabular}{|c|c|c|c|}
\hline Parameter & Over expression & Under expression & $\mathbf{P}$ \\
\hline Number & 33 & 7 & \\
\hline \multicolumn{4}{|c|}{ Outcome after induction therapy } \\
\hline Remission & $26(78.8 \%)$ & $0(0 \%)$ & $<0.001^{*}$ \\
\hline Non remission & $7(21.2 \%)$ & $7(100 \%)$ & \\
\hline
\end{tabular}

*Very Significant $\mathrm{p}<0.005$. 


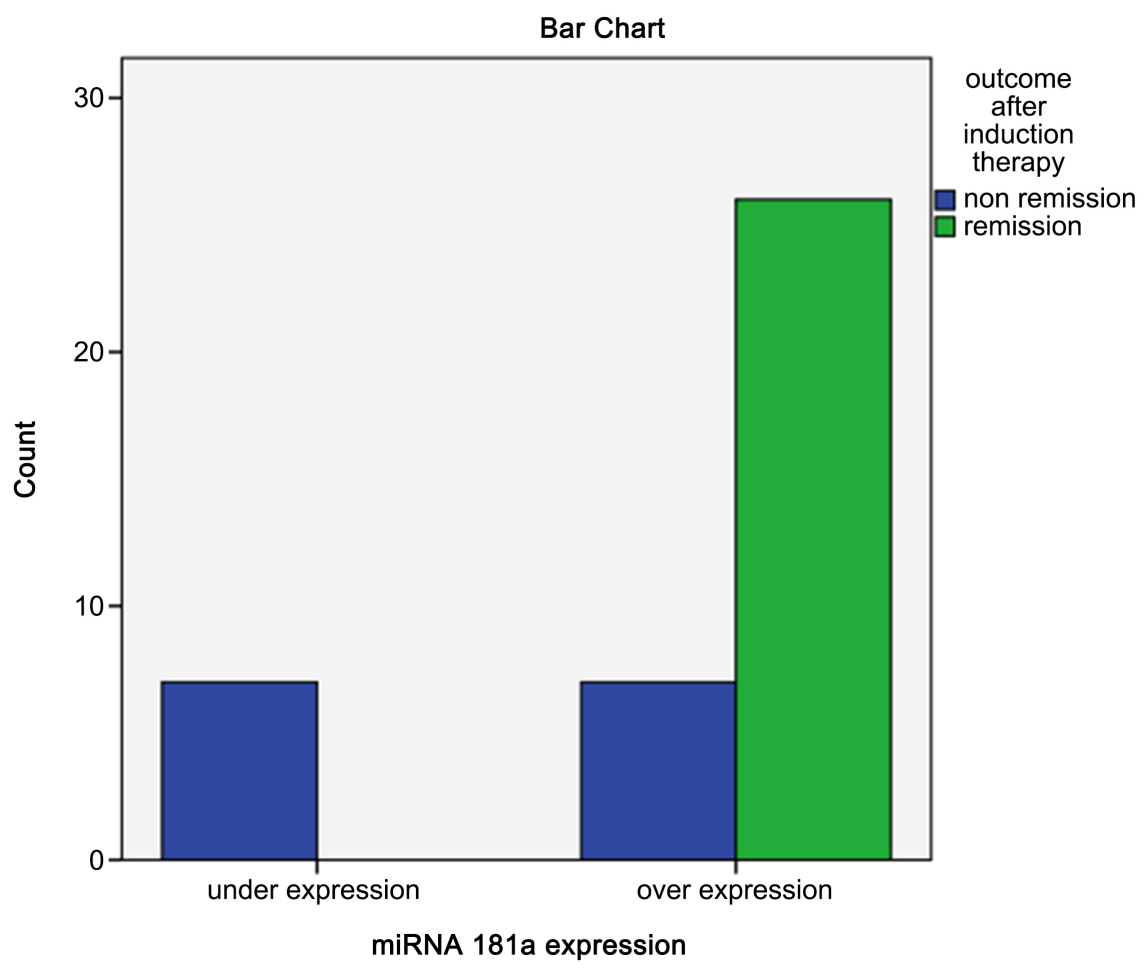

Figure 1. Association between miR-181a expression and the outcome after induction therapy.

We found no significant difference between high and low expresser of miR-181a as regard to sex, hepatosplenomegaly, WBCs level and generalized lymphadenopathy in these patients. Neither was the significant difference between high and low miRNA 181 expresser as regard to immunophenotyping and $t(9 ; 22)$ in these patients.

These results agreed with El-Khazragy et al. [13] study that concluded no significant correlation between miR-181a expression and each of the following: age, sex, WBCs count and immunophenotyping in pediatric ALL patients.

Yan et al. [14] disagreed with our result, reported that miR-181a expression was upregulated in T-ALL.

As regard to response after induction therapy, we found significant relationship between expression of miR-181a and the outcome after induction therapy in which patient with over expression of miR-181a developed remission and had a good response to induction therapy.

This finding is in parallel with Wang JJ \&Yu JP [15] study proved that miR-181a over expression inhibited leukemia cell proliferation, induced apoptosis, and reduced Adriamycin resistance. Also, our result is supported by the previous meta-analysis. Lin et al. [16] reported that high expressed miR-181a could prolong overall survival (OS) in patients with hematological malignancies including ALL. Also, our result is in line with Li et al. [17] and Bai et al. [18] concluded that over expression of miR-181a sensitizes leukemia cells to daunorubicin and cytarabine treatment, respectively. 
El-Khazragy et al. [13] could not find a link between the expression of miRNA-181a in pediatric ALL and the prognosis.

In the contrary, Zhu et al. [19] found that the expression of miR-181a in favorable prognosis group was significantly lower than in poor prognosis group. Also our result disagreed with Han et al. [20] who proved that miR-181a was upregulated with higher fold changes in the relapse samples compared with complete remission samples in pediatric ALL case and Wang et al. [21] who determined that increased expression of miR-181a was associated with a poor outcome.

\section{Conclusion}

We conclude that miR181 over expression is associated with good response to the induction therapy and hence good outcome, which may help provide new insights into the disease monitoring and treatment response of childhood ALL. This also will help clinicians to divide patient to high and low risk group with different treatment strategies according to miR181 expression.

\section{Conflicts of Interest}

The authors declare no conflicts of interest regarding the publication of this paper.

\section{References}

[1] Pui, C.H. (2010) Recent Research Advances in Childhood Acute Lymphoblastic Leukemia. Journal of the Formosan Medical Association, 109, 777-787. https://doi.org/10.1016/S0929-6646(10)60123-4

[2] Coustan-Smith, E., Song, G., Clark, C., Key, L., Liu, P., Mehrpooya, M., Stow, P., Su, X., Shurtleff, S., Pui, C.H., Downing, J.R. and Campana, D. (2011) New Markers for Minimal Residual Disease Detection in Acute Lymphoblastic Leukemia. Blood, 117, 6267-6276. https://doi.org/10.1182/blood-2010-12-324004

[3] Zhou, X., Wen, W., Shan, X., Zhu, W., Xu, J., Guo, R., Cheng, W., Wang, F., Qi, L.W., Chen, Y., Huang, Z., Wang, T., Zhu, D., Liu, P. and Shu, Y. (2017) A Six-microRNA Panel in Plasma Was Identified as a Potential Biomarker for Lung Adenocarcinoma Diagnosis. Oncotarget, 8, 6513-6525. https://doi.org/10.18632/oncotarget.14311

[4] Tombak, A., Gorur, A., Balci, S., Tiftik, N. and Tamer, L. (2015) Circulating microRNAs in Newly Diagnosed Acute and Chronic Leukemias. International Journal of Hematology and Oncology, 25, 75-80.

[5] Li, X.J., Luo, X.Q., Han, B.W., Duan, F.T., Wei, P.P. and Chen, Y.Q. (2013) MicroRNA-100/99a, Deregulated in Acute Lymphoblastic Leukaemia, Suppress Proliferation and Promote Apoptosis by Regulating the FKBP51 and IGF1R/mTOR Signalling Pathways. British Journal of Cancer, 109, 2189-2198. https://doi.org/10.1038/bjc.2013.562

[6] Yan, J., Jiang, N., Huang, G., Tay, J.L., Lin, B., Bi, C., Koh, G.S., Li, Z., Tan, J., Chung, T.H., Lu, Y., Ariffin, H., Kham, S.K., Yeoh, A.E. and Chng, W.J. (2013) Deregulated MIR335 That Targets MAPK1 Is Implicated in Poor Outcome of Paediatric Acute Lymphoblastic Leukaemia. British Journal of Haematology, 163, 93-103. 
https://doi.org/10.1111/bjh.12489

[7] Burke, M.J. and Bhatla, T. (2014) Epigenetic Modifications in Pediatric Acute Lymphoblastic Leukemia. Frontiers in Pediatrics, 2, 42.

https://doi.org/10.3389/fped.2014.00042

[8] Li, W.Y., Chen, X.M., Xiong, W., Guo, D.M., Lu, L. and Li, H.Y. (2014) Detection of Microvesicle miRNA Expression in ALL Subtypes and Analysis of Their Functional Roles. Journal of Huazhong University of Science and Technology (Medical Science), 34, 640-645. https://doi.org/10.1007/s11596-014-1330-0

[9] de Oliveira, J.C., Scrideli, C.A., Brassesco, M.S., Morales, A.G., Pezuk, J.A., Queiroz Rde, P., Yunes, J.A., Brandalise, S.R. and Tone, L.G. (2012) Differential miRNA Expression in Childhood Acute Lymphoblastic Leukemia and Association with Clinical and Biological Features. Leukemia Research, 36, 293-298.

https://doi.org/10.1016/j.leukres.2011.10.005

[10] Belkaya, S., Silge, R.L., Hoover, A.R., Medeiros, J.J., Eitson, J.L., Becker, A.M., de la Morena, M.T., Bassel-Duby, R.S. and van Oers, N.S. (2011) Dynamic Modulation of Thymic microRNAs in Response to Stress. PLoS ONE, 6, e27580.

https://doi.org/10.1371/journal.pone.0027580

[11] Neilson, J.R., Zheng, G.X., Burge, C.B. and Sharp, P.A. (2007) Dynamic Regulation of miRNA Expression in Ordered Stages of Cellular Development. Genes \& Development, 21, 578-589. https://doi.org/10.1101/gad.1522907

[12] Duyu, M., Durmaz, B., Gunduz, C., Vergin, C., Yilmaz Karapinar, D., Aksoylar, S., Kavakli, K., Cetingul, N., Irken, G., Yaman, Y., Ozkinay, F. and Cogulu, O. (2014) Prospective Evaluation of Whole Genome microRNA Expression Profiling in Childhood Acute Lymphoblastic Leukemia. BioMed Research International, 2014, Article ID: 967585. https://doi.org/10.1155/2014/967585

[13] El-Khazragy, N., Noshi, M.A., Abdel-Malak, C., Zahran, R.F. and Swellam, M. (2019) miRNA-155 and miRNA-181a as Prognostic Biomarkers for Pediatric Acute Lymphoblastic Leukemia. Journal of Cellular Biochemistry, 120, 6315-6321. https://doi.org/10.1002/jcb.27918

[14] Yan, Z.X., Zheng, Z., Xue, W., Zhao, M.Z., Fei, X.C., Wu, L.L., Huang, L.M., Leboeuf, C., Janin, A., Wang, L. and Zhao, W.L. (2015) MicroRNA181a Is Overexpressed in T-Cell Leukemia/Lymphoma and Related to Chemoresistance. BioMed Research International, 2015, Article ID: 197241. https://doi.org/10.1155/2015/197241

[15] Wang, J.J. and Yu, J.P. (2019) miR-181a Down-Regulates MAP2K1 to Enhance Adriamycin Sensitivity in Leukemia HL-60 Cells. European Review for Medical and Pharmacological Sciences, 23, 2497-2504.

[16] Lin, S., Pan, L., Guo, S., Wu, J., Jin, L., Wang, J.C. and Wang, S. (2013) Prognostic Role of microRNA-181a/b in Hematological Malignancies: A Meta-Analysis. PLoS ONE, 8, e59532. https://doi.org/10.1371/journal.pone.0059532

[17] Li, H., Hui, L. and Xu, W. (2012) miR-181a Sensitizes a Multidrug-Resistant Leukemia Cell Line K562/A02 to Daunorubicin by Targeting BCL-2. Acta Biochimica et Biophysica Sinica (Shanghai), 44, 269-277. https://doi.org/10.1093/abbs/gmr128

[18] Bai, H., Cao, Z., Deng, C., Zhou, L. and Wang, C. (2012) miR-181a Sensitizes Resistant Leukaemia HL-60/Ara-C Cells to Ara-C by Inducing Apoptosis. Journal of Cancer Research and Clinical Oncology, 138, 595-602.

https://doi.org/10.1007/s00432-011-1137-3

[19] Zhu, Y.D., Wang, L., Sun, C., Fan, L., Zhu, D.X., Fang, C., Wang, Y.H., Zou, Z.J., Zhang, S.J., Li, J.Y. and Xu, W. (2012) Distinctive microRNA Signature Is Asso- 
ciated with the Diagnosis and Prognosis of Acute Leukemia. Medical Oncology, 29, 2323-2331. https://doi.org/10.1007/s12032-011-0140-5

[20] Han, B.W., Feng, D.D., Li, Z.G., Luo, X.Q., Zhang, H., Li, X.J., Zhang, X.J., Zheng, L.L., Zeng, C.W., Lin, K.Y., Zhang, P., Xu, L. and Chen, Y.Q. (2011) A Set of miRNAs That Involve in the Pathways of Drug Resistance and Leukemic Stem-Cell Differentiation Is Associated with the Risk of Relapse and Glucocorticoid Response in Childhood ALL. Human Molecular Genetics, 20, 4903-4915.

https://doi.org/10.1093/hmg/ddr428

[21] Wang, Y., Li, Z., He, C., Wang, D., Yuan, X., Chen, J. and Jin, J. (2010) MicroRNAs Expression Signatures Are Associated with Lineage and Survival in Acute Leukemias. Blood Cells, Molecules and Diseases, 44, 191-197.

https://doi.org/10.1016/j.bcmd.2009.12.010 